\title{
MIGRACÃO DO POVO INDÍGENA SATERÉ-MAWÉ EM DOIS CONTEXTOS URBANOS DISTINTOS NA AMAZÔNIA
}

\author{
Pery Teixeira* \\ Evelyne Marie Therese Mainbourg ${ }^{* *}$ \\ Marilia Brasil ${ }^{* *}$
}

\begin{abstract}
Partindo de informações levantadas em duas pesquisas de campo - uma censitária e outra amostral - referentes a distintas áreas urbanas do estado do Amazonas, este trabalho procura fornecer subsídios para a compreensão da migração indígena com destino urbano na Amazônia, com enfoque principal no povo indígena Sateré-Mawé. Trata-se de um estudo comparativo entre características migratórias dos Sateré-Mawé residentes em Manaus, capital do estado do Amazonas, e os que moram nas cidades próximas às terras indígenas de origem daquele povo, no leste do estado. Apesar da semelhança de algumas das características do processo migratório nos dois contextos - motivados pela procura de trabalho e por oportunidades de educação , observa-se diferenciação na importância dessas causas em cada contexto, além de ocorrerem distinções na faixa etária e na distribuição por sexo dos migrantes.

Palavras-CHAVE: migração de povos indígenas, Sateré-Mawé, demografia de povos indígenas, índios.
\end{abstract}

\section{INTRODUÇÃO}

Entre os fenômenos demográficos relacionados à população indígena que estão a exigir aprofundamento e detalhamento de análise encontra-se a migração, especialmente a que se dá em direção às cidades. Os processos migratórios constituem fenômenos ainda pouco estudados, embora estejam se tornando cada vez mais frequentes, como decorrência, entre outros fatores, da absorção do indígena nos mercados regionais, dos conflitos por terra e da insuficiente infraestrutura e disponibilidade de serviços essenciais (como os de saúde e educação) nas terras indígenas (Coimbra Jr.; Santos, 2000, p.3).

Ainda mais escassos são os estudos demográficos sobre o tema, com base, geralmente,

* Doutor em Demografia. Professor Adjunto da Universidade Federal Amazonas (UFAM). Pesquisador e membro da Coordenação do Programa de Pós-Graduação em Desenvolvimento Regional (PRODERE)

Av. Gen. Rodrigo Otávio J. Ramos, 3000. Aleixo. Cep: 69077000 - Manaus, AM - Brasil. periteixeira@uol.com.br

* * Doutora em Ciências Sociais. Pesquisadora da Fundacão Oswaldo Cruz de Manaus e colaboradora do Centro de Ciências do Ambiente da Universidade Federal do Amazonas. evelyne@amazonia.fiocruz.br

***Doutoranda em Saúde Coletiva pela Fundação Oswaldo Cruz (FIOCRUZ). marilia.brasil@ymail.com em dados censitários ou coletados em levantamentos específicos de campo, a maioria dos quais realizados a partir do ano 2000. Enquadram-se nessa linha os trabalhos que tratam especificamente da migração indígena ou que a abordam em contexto mais amplo (Coimbra Jr.; Santos, 2000; Pereira; Azevedo, 2004; Pereira et al., 2005; Teixeira, 2005; Brasil, 2006; Oliveira, 2008, Teixeira; Sena, 2008; Pinho; Campos, 2008; Dias Júnior et al.; Mainbourg et al., 2008).

Embora constituam fonte obrigatória para o estudo da migração indígena, os dois últimos censos demográficos brasileiros (1991 e 2000) apresentam limitações que devem ser tomadas em consideração cada vez que se aborde o assunto. A principal delas é a dificuldade de se trabalhar com pequenos números, especialmente para unidades menores de análise, como municípios ou bairros, áreas urbanas ou rurais, já que a população indígena representa somente $0,4 \%$ do total brasileiro. O caráter amostral das informações levantadas restringe a análise de importantes variáveis apenas aos agrupamentos indígenas mais significativos demograficamente, seja em área urbana ou rural. 
Assim, por exemplo, para as variáveis relacionadas à migração, a análise deve-se limitar aos dados estaduais, metropolitanos, macro ou microrregionais, ou aos referentes aos municípios com maior concentração de indígenas.

Alguns levantamentos demográficos e participativos de caráter censitário, com quesitos relacionados à migração, têm sido realizados junto a populações indígenas específicas da Amazônia. No estado do Amazonas, a Federação das Organizações Indígenas do Alto Rio Negro (FOIRN) e o Instituto Sócio-Ambiental (ISA) realizaram um recenseamento nas terras indígenas do Alto Rio Negro, em 1992, e outro em 2006, na cidade de São Gabriel da Cachoeira, na mesma região (Azevedo, 1994, 2006). Em 2003, um censo demográfico ${ }^{1}$ foi realizado nas comunidades de residência do povo Sateré-Mawé (Terra Indígena Andirá-Marau) e em cidades próximas, todas no Amazonas, numa associação entre instituições governamentais, organizações indígenas e agências das Nações Unidas (Teixeira, 2005). Mais recentemente (2007), no âmbito de uma pesquisa amostral da FIOCRUZ sobre o acesso da população indígena de Manaus ao Sistema Único de Saúde (SUS), ${ }^{2}$ alguns quesitos sobre migração foram incluídos no formulário do levantamento (Mainbourg et al., 2008). Os Sateré-Mawé, povo indígena ao qual se refere o presente estudo, constituem importante contingente dos imigrantes indígenas de Manaus.

O objetivo do presente trabalho é estudar, sob o enfoque demográfico, a migração dos SateréMawé para as cidades próximas da Terra Indígena Andirá-Marau e para a capital amazonense, com base nas informações obtidas nos dois últimos levantamentos mencionados.

\section{Aspectos metodológicos}

Dois contextos migratórios que abrangem o povo indígena Sateré-Mawé serão enfocados, in-

${ }^{1}$ Diagnóstico Sócio-Demográfico Participativo da População Sateré-Mawé.

${ }^{2}$ População Indígena da Cidade de Manaus: Condições de Saúde e SUS. dividual e comparativamente, como forma de se procurar entender a migração indígena para curtas e longas distâncias. Num primeiro momento, serão estudadas algumas características dos fluxos migratórios que, a partir das terras indígenas de origem desse povo, destinam-se a quatro cidades situadas nas proximidades daquelas terras, nos mesmos municípios onde elas se situam $O$ estudo utiliza informações quantitativas a respeito da intensidade da migração, da distribuição por sexo e idade dos migrantes, das suas causas e do tempo de residência na cidade de destino. Como tais fatores podem estar associados entre si, as informações são cruzadas para a análise, quando necessário.

Para o estudo desse processo migratório com destino a cidades interioranas, serão utilizadas informações obtidas em levantamento censitário realizado em 2002 e $2003^{3}$ (Teixeira, 2005), nas cidades de Parintins, Barreirinha, Maués e Nova Olinda do Norte. A pesquisa teve como entrevistadores professores e estudantes indígenas. Foi aplicada a técnica do tipo "bola-de-neve", em que os próprios entrevistados indicavam outras pessoas e famílias a serem visitadas. Acredita-se que, com algumas exceções, a totalidade dos Sateré-Mawé residentes nessas cidades foi coberta pelo levantamento. Quesitos sobre habitação, demografia, saúde, educação, idioma escrito e falado, emprego e renda compuseram o formulário da pesquisa. Os quesitos do componente demográfico do formulário contemplavam vários aspectos do processo migratório, como local de nascimento, residências anteriores, condição de nascimento ou não em terra indígena, município e estado de nascimento e de residência anterior, tempo de residência na cidade de moradia atual e motivos da migração. Os quesitos sobre migração destinaram-se a moradores com idade igual ou superior a 10 anos.

Um artigo publicado nos Anais do XVI Encontro Brasileiro de Estudos Populacionais, em 2008, com base no Levantamento SócioDemográfico Participativo de 2002/2003, aborda os

3 Trata-se do Diagnóstico Socio-Demográfico participativo da população Sateré-Mawé, já citado. 
deslocamentos no interior da Terra Indígena AndiráMarau e para as cidades interioranas próximas (Teixeira, 2008). É retomado aqui, com as modificações devidas, o capítulo do referido artigo que aborda a migração para aquelas cidades.

Outro contexto migratório estudado referese à cidade de Manaus, capital do estado do Amazonas. Aqui, também, a migração é analisada segundo as características já abordadas nas cidades interioranas, vizinhas das terras dos Sateré-Mawé. A análise será complementada com estudos comparativos, de um lado, dos migrantes sateré-mawé com os pertencentes a outros povos indígenas moradores da capital e, de outro, dos migrantes sateré-mawé de Manaus com os que se destinam àquelas outras cidades.

A análise da migração dos Sateré-Mawé para a cidade de Manaus tem como base quantitativa uma pesquisa amostral realizada pela Fundação Oswaldo Cruz (FIOCRUZ) em 2007 (Mainbourg et al., 2008). Trata-se de um estudo que compara o atendimento prestado pelo Sistema Único de Saúde (SUS) em Manaus às populações indígenas e não-indígenas. A pesquisa baseia-se em levantamento amostral de 753 indígenas de 47 etnias quase todas originárias do estado do Amazonas e 874 não-indígenas, tendo como entrevistadores professores e estudantes indígenas do município de Manaus, indicados pelas correspondentes associações de moradores indígenas.

Como subsídio à análise dos dados a respeito do atendimento à saúde dos entrevistados, o formulário da pesquisa de campo incluiu vários quesitos sobre a condição sociodemográfica dos moradores. Da mesma forma que no levantamento sobre a migração em direção a cidades interioranas (Mainbourg et al., 2008), foram entrevistados indígenas com 10 anos ou mais, e os quesitos sobre a migração levantaram informações sobre condição de naturalidade, município e estado de nascimento e de última moradia, tempo de residência no município e motivo da migração.

\section{LOCALIZAÇÃO GEOGRÁFICA DA POPULA- ÇÃOSATERÉ-MAWÉ}

A quase totalidade do território dos SateréMawé é composta pela Terra Indígena AndiráMarau, que está situada na divisa dos estados do Amazonas e Pará. O seu processo de demarcação foi iniciado em 1978, sendo interrompido por dois anos, período caracterizado por várias ameaças de invasão. Destaca-se, entre elas, o projeto de construção da estrada que liga Maués a Itaituba, que cortaria a terra indígena ao meio, e a prospecção de petróleo protagonizada pela empresa petrolífera francesa Elf-Aquitaine. A demarcação foi finalmente oficializada em 1982 e homologada em 1986 (Teixeira, 2005). Posteriormente, ocorreram penetrações esporádicas de garimpeiros e de posseiros moradores dos limites fronteiriços da Terra Indígena. Atualmente, o risco de invasão do território Sateré-Mawé está de volta por conta de grileiros ligados ao agronegócio no município de Itaituba (PA), onde se encontram várias aldeias da Terra Indígena Andirá-Marau.

Uma parcela reduzida do povo Sateré-Mawé reside numa aldeia situada na Terra Indígena KoatáLaranjal, do povo Munduruku, no município de Borba (AM), a uma centena de quilômetros do Andirá-Marau. Três famílias de migrantes dessa aldeia moram na cidade de Nova Olinda do Norte, situada no município de mesmo nome, e bastante próxima à referida comunidade.

Em 2003, por ocasião da pesquisa de campo referente ao Levantamento Sócio-Demográfico Participativo (Teixeira, 2005), a população SateréMawé que residia em área indígena e nas cidades de Barreirinha, Maués, Parintins Nova Olinda do Norte e Manaus chegava a, aproximadamente, 9.000 habitantes. No Andirá-Marau havia 91 aldeias distribuídas ao longo dos principais rios e igarapés que cortam a terra dos Sateré-Mawé e onde viviam, em exatamente 1.500 domicílios, 7.375 habitantes. A área mais povoada do Andirá-Marau localiza-se ao longo do Rio Andirá e seus principais tributários, no município de Barreirinha, onde existem 50 aldeias. Segunda área em população, a 
região banhada pelos rios Marau, Urupadi e Miriti, com 37 aldeias, localiza-se nos municípios de Maués (AM) e Itaituba (PA). Num patamar demográfico mais reduzido está a área do rio Uaicurapá, no município de Parintins, com quatro aldeias. A aldeia situada na Terra Indígena Koatá-Laranjal possui 31 residências, com 127 moradores (Tabela 1).

Tabela 1 - População Sateré-Mawé segundo o quadro de residência e sexo

Área indígena e área urbana - 2002-2003

\begin{tabular}{l|c|c|c}
\multicolumn{4}{c}{ Área indígena érea urbana - 2002-2003 } \\
\hline Local de residência & $\begin{array}{c}\text { No. de } \\
\text { comunidades }\end{array}$ & $\begin{array}{c}\text { No. de } \\
\text { domicílios }\end{array}$ & População \\
\hline Área indígena & 92 & 1531 & 7.502 \\
\hline Andirá & 50 & 779 & 3.795 \\
\hline Marau & 37 & 662 & 3.288 \\
\hline Uaicurapá & 4 & 59 & 292 \\
\hline Koatá-Laranjal & 1 & 31 & 127 \\
\hline Área urbana & - & 228 & 998 \\
\hline Parintins & - & 127 & 512 \\
\hline Barreirinha & - & 50 & 276 \\
\hline Maués & - & 48 & 200 \\
\hline Nova Olinda do Norte & - & 3 & 10 \\
\hline Área rural não-indígena & - & - & $300^{*}$ \\
\hline Cidade de Manaus & - & - & $600^{*}$ \\
\hline Total & & & 9400 \\
\hline
\end{tabular}

Fonte: Base de dados do Diagnóstico Sócio-Demográfico Participativo da População Sateré-Mawé.

* População estimada pelos autores.

Dentre as cidades situadas na vizinhança da área indígena, a mais habitada pelos SateréMawé é Parintins, importante centro urbano do Amazonas e onde se concentram o comércio e os serviços mais dinâmicos do leste do estado. Barreirinha vem em seguida, com pouco mais da metade da população Sateré-Mawé de Parintins. Por sua vez, apenas três domicílios são habitados pelos Sateré-Mawé na cidade de Nova Olinda do Norte, próxima a uma aldeia desse povo situada em terra Munduruku. Essa reduzida população reflete a exiguidade demográfica da aldeia em questão, que tem apenas 127 habitantes.

Em Manaus, capital do estado do Amazonas, vive uma expressiva quantidade de SateréMawé, composta por migrantes, seus filhos e netos. A chegada dos primeiros migrantes à cidade deu-se, provavelmente, como consequência da implantação da Zona Franca de Manaus, em 1967, conforme se verá mais adiante.

Embora difícil de quantificar, observa-se um contingente não-negligenciável de Sateré-Mawé em áreas rurais próximas à Terra Indígena AndiráMarau. Trata-se de famílias que, apesar de manterem vínculos culturais e sociais com a terra de origem, optaram por viver em suas proximidades. Os dados disponibilizados do censo demográfico não permitem distinguir numericamente indígenas moradores das terras indígenas dos que habitam na zona rural, razão pela qual o número de 300 residentes em áreas rurais, mostrados na Tabela 1, resulta de uma estimativa feita pelos autores, a qual teve como parâmetro o total de migrantes residentes nas cidades próximas às terras indígenas e nascidos nas áreas rurais vizinhas.

\section{CONSIDERAÇÕES SOBRE A MIGRA- ÇÃO INDÍGENA PARA AS CIDADES}

Os elementos básicos de determinação dos deslocamentos da população indígena para as cidades amazônicas no Século XX devem ser procurados no contexto histórico em que se deram as transformações sociais e econômicas no Brasil, especialmente a partir dos anos cinquenta, com consequências nas áreas rurais e indígenas da Amazônia.

Ocorrendo de forma simultânea ao processo de urbanização, o progresso técnico e o desenvolvimento dos transportes facilitaram a comunicação entre as pessoas e as instituições, promovendo as condições econômicas, operacionais e ideológicas que permitiram a transferência de milhões de brasileiros das áreas rurais para as cidades próximas e, dessas, para as aglomerações urbanas de grande porte, ou diretamente da zona rural para as cidades de médio e grande porte.

Com o correr do tempo, as transformações que ocorriam no país passaram a ter reflexos no cotidiano da população indígena. Grande parte dela, ou por não ter legalizada a terra em que vivia, não 
possuir meios de nela sobreviver, não desfrutar condignamente de serviços sociais básicos, ou simplesmente ser atraída pela vida urbana (especialmente os jovens), acabou por migrar para as cidades. No censo demográfico brasileiro de 2000, mais da metade da população que se declarou indígena vivia no meio urbano. Na Região Norte, a proporção correspondente era de 23\% (IBGE, 2005).

A migração para as cidades próximas das terras indígenas dá-se no âmbito do processo de urbanização no Brasil, o qual tem caído de intensidade nas áreas mais desenvolvidas, com tendência a reduzir-se também na Região Norte. A capital do Amazonas, Manaus, constitui o destino preferido dos migrantes interioranos desse estado, quando se considera o conjunto da população (indígenas e não-indígenas). De uma maneira geral, a primeira etapa do processo migratório inicia-se com a mudança da população rural para a área urbana dos municípios próximos. Esse fenômeno ocorre também com a migração indígena, mas há especificidades que diferenciam essa última do processo migratório da população abrangente.

Várias situações podem determinar o movimento migratório dos indígenas em direção aos aglomerados urbanos, as quais, segundo Baines (2001), vão desde aquelas em que os indígenas são expulsos das suas terras, até outras situações em que optam pela vida na cidade em decorrência da falta de oportunidades de educação e atendimento adequado de saúde nas suas aldeias. O processo ocorre de formas diversas,

desde o traslado de grupos familiares para bairros onde já há um contingente grande de índios organizados politicamente até casos de migração de indivíduos para a cidade em busca de empregos, tratamento de saúde, educação ou um novo estilo de vida (Baines, 2001).

Os condicionantes da migração indígena em direção às cidades têm como aliados importantes o progresso e a universalização dos meios de comunicação de massa, bem como as facilidades crescentes de locomoção na área indígena e, dela, em direçãoà cidade, considerada, cada vez mais, como referência para a satisfação de necessidades antigas e novas.

\section{AMIGRAÇÃO DOS SATERÉ-MAWÉ-DA TERRA INDÍGENA PARA AS CIDADES PRÓXIMAS}

Cerca de 20\% dos Sateré-Mawé vivem fora das terras indígenas (Tabela 1), seja nas cidades e áreas rurais vizinhas à Terra indígena Andirá-Marau ou em Manaus. Os determinantes desse significativo deslocamento estão relacionados aos contatos cada vez mais intensos com a população não-indígena, proporcionados, por sua vez, pelo acesso crescente aos meios de informação e pela relativa facilidade de locomoção. Esses fatores determinantes relacionam-se não apenas com as mudanças que ocorreram e ocorrem na sociedade envolvente, como também com as transformações econômicas, sociais e culturais no interior das comunidades indígenas, tendo como pano de fundo a degradação das condições de subsistência nos territórios onde elas se situam.

Em dissertação de mestrado sobre as condições de vida dos Sateré-Mawé residentes em Manaus, Romano afirma que a causa determinante da saída desse povo da área indígena foi a desestruturação do seu modo de vida tradicional. O autor intenta "trazer elementos para a reflexão sobre os problemas da etnicidade em áreas urbanas" (Romano, 1982, p.7). Com esse objetivo, procurava descrever as peculiaridades do processo migratório e da qualidade de vida dos Sateré-Mawé, reconstruir a presença simbólica do indígena e apreender os mecanismos de identificação étnica, buscando entender como essa presença simbólica incide sobre sua situação.

Mensalmente, os assalariados e aposentados Sateré-Mawé, geralmente acompanhados da família, vão às cidades próximas das aldeias para receber proventos, fazer compras, visitar parentes, consultar o médico, etc. Os filhos que estudam nessas cidades mantêm vínculo permanente e intenso com suas famílias, embora alguns acabem não retornando mais à aldeia de origem. Todavia, para todos eles, a terra que deixam continua sendo sua referência principal, havendo sempre a perspectiva do retorno.

Nas quatro cidades próximas à área indíge- 
na, foram recenseados 998 Sateré-Mawé (478 homens e 525 mulheres), dos quais 678 com 10 anos ou mais de idade. Desses últimos, 570, que serão designados doravante como "migrantes", declararam não ser naturais das cidades em que residiam e constituirão a população a ser estudada.

Como se observa na Tabela 2, para quase $80 \%$ dos migrantes das cidades em foco, o local de nascimento é a terra indígena, mas uma parcela significativa nasceu em áreas rurais próximas àquelas terras. Um contingente menor declarou ter nascido em outras cidades, especialmente Manaus (12 entrevistados).

Tabela 2 - Cidades de Parintins, Barreirinha, Maués e Nova Olinda do Norte

Local de nascimento dos migrantes saterémawé - 2002/2003

\begin{tabular}{l|c|c}
\hline \multirow{2}{*}{ Local de nascimento } & \multicolumn{2}{|c}{ População migrante } \\
\cline { 2 - 3 } & Efetivos & $\%$ \\
\hline Terra Indígena & 448 & 78,6 \\
\hline Área rural & 87 & 15,3 \\
\hline Outras cidades & 28 & 4,9 \\
\hline Não sabe/não informou & 7 & 1,2 \\
\hline Total de migrantes urbanos & 570 & 100,0 \\
\hline
\end{tabular}

Fonte: Extraído de Teixeira e Sena, 2008. des e, mesmo entre os idosos, ainda é significativa. Isso ocorre porque, na realidade, quase todos os moradores Sateré-Mawé com mais de 30 anos de idade daquelas cidades são migrantes: de 231 moradores nessa faixa etária, apenas 11 eram naturais delas quando foi realizada a pesquisa entre 2002 e 2003.

As mulheres são pequena maioria, relativamente aos homens, entre os migrantes $(51,4 \%$ do total), mas essa superioridade numérica manifesta-se irregularmente entre os grupos etários (Figura 1). Até os 20 anos, os homens são ligeiramente mais numerosos. A partir daí, as mulheres passam a representar, em média, $57 \%$ dos migrantes. Não seria temerário deduzir, a partir da observação da figura, que a expressiva participação de adultos e idosos na população Sateré-Mawé migrante, conforme visto no parágrafo anterior, pode estar relacionada à supremacia feminina nessas idades, para esses efetivos populacionais.

Há uma relação entre a distribuição etária e por sexo dos migrantes Sateré-Mawé e os motivos de migrar para as cidades próximas da terra indígena. Os dois motivos mais citados nas entrevis-

Figura 1 - Área urbana - Distribuição da população migrante por idade e sexo - 2002/2003

Estrutura demográfica e motivo da migração

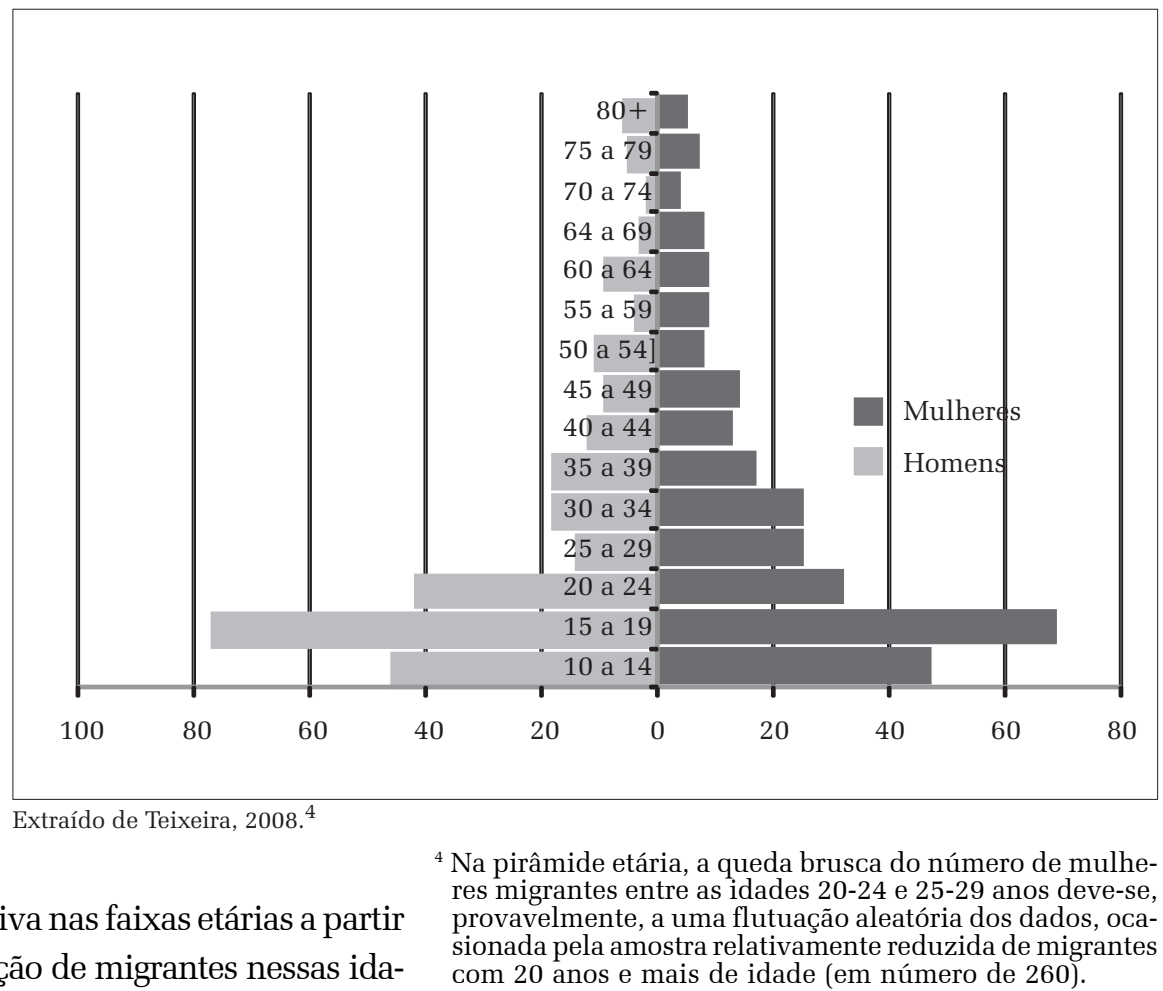


tas, conforme se observa na Tabela 3, são a busca por melhores condições de educação (49\% dos migrantes) e o acompanhamento dos pais em sua mudança de residência (29\%). ciação entre os motivos de migrar dos homens e mulheres Sateré-Mawé. A transferência de trabalho, por exemplo, mesmo sendo citada por poucas pessoas como motivo da migração, é uma ca-

Tabela 3 - Cidades de Parintins, Barreirinha, Maués e Nova Olinda do Norte Motivo de migrar para a cidade segundo a idade e o sexo dos migrantes - 2002/2003

\begin{tabular}{|c|c|c|c|c|c|c|c|c|c|}
\hline \multirow{3}{*}{ Motivo da migração } & \multicolumn{9}{|c|}{ Faixa etária } \\
\hline & \multicolumn{3}{|c|}{$10-29$ anos } & \multicolumn{3}{|c|}{30 anos e mais } & \multicolumn{3}{|c|}{ Todas as idades } \\
\hline & Masc. & Fem. & Total & Masc. & Fem. & Total & Masc. & Fem. & Total \\
\hline Transferência de trabalho & 1 & 1 & 2 & 12 & 2 & 14 & 13 & 3 & 16 \\
\hline Procura de trabalho & 1 & 13 & 14 & 6 & 4 & 10 & 7 & 17 & 24 \\
\hline $\begin{array}{l}\text { Procura de melhores condições } \\
\text { de educação }\end{array}$ & 104 & 78 & 182 & 42 & 54 & 96 & 146 & 132 & 278 \\
\hline Acompanhando os pais & 69 & 72 & 141 & 10 & 12 & 22 & 79 & 84 & 163 \\
\hline Outro motivo & 6 & 20 & 26 & 26 & 37 & 63 & 32 & 57 & 89 \\
\hline Total & 181 & 184 & 365 & 96 & 109 & 205 & 277 & 293 & 570 \\
\hline
\end{tabular}

Fonte: Base de dados do Diagnóstico Sócio-Demográfico Participativo da População Sateré-Mawé.

Uma parcela substancial dos migrantes indígenas costuma deslocar-se juntamente com a própria família, e isso ocorre-como entre os SateréMawé - para que os familiares mais jovens ingressem nas escolas situadas em área urbana. A migração familiar por motivos educacionais realça a importância que os pais dão à continuidade da escolarização dos filhos, bastante reduzida na terra indígena (na época da pesquisa de campo, apenas uma escola oferecia nível de ensino acima da Quarta Série do Fundamental).

Os resultados do Diagnóstico Sóciodemográfico Participativo (Teixeira, 2005) indicam que uma quantidade significativa de adolescentes e jovens Sateré-Mawé que migram para estudar o fazem desacompanhados de suas famílias. Ali, hospedam-se em residência de parentes ou, em alguns casos, na "Casa do Estudante Indígena", como a que existe na cidade de Maués. Tal situação, para as famílias desses jovens, parece estar relacionada à falta de condições financeiras, às dificuldades de instalação, adaptação e sobrevivência do grupo familiar na cidade, ao apego à terra ancestral ou, ainda, à necessidade objetiva da família de continuar morando na terra indígena, condicionada por fatores econômicos, sociais ou políticos.

Os dados deixam transparecer uma diferen- racterística basicamente masculina. Entre os 28 funcionários públicos indígenas residentes nessas cidades (em igual número de homens e mulheres), há seis migrantes, todos homens, que se mudaram por motivo de transferência de trabalho. Nenhuma mulher do serviço público o fez pelo mesmo motivo. Por outro lado, a migração motivada pela procura de trabalho (citada por apenas $4 \%$ dos migrantes) constitui uma prerrogativa majoritária das mulheres jovens (entre10 e 29 anos). Entre as migrantes dessa faixa etária, 10 alegaram a procura de trabalho como motivo de migrar, o que não foi citado por nenhum homem dessa mesma faixa. A partir de 30 anos de idade, há igualdade numérica para homens e mulheres que migraram por esse motivo. ${ }^{5}$

É diferente quando se considera a migração motivada pela procura de melhores condições de educação. Até os 29 anos de idade, são os homens que constituem maioria dos que declararam essa causa. Eles são 104, contra 78 mulheres nessa situação. A partir da idade de 30 anos, ${ }^{6}$ quando cai

${ }^{5}$ No total, 25 indígenas (18 mulheres e sete homens) declararam ter migrado à procura de trabalho.

${ }^{6} \mathrm{Na}$ tabela mostrada, relativamente aos mais jovens, o menor número de migrantes com 30 anos e mais que se mudaram em busca de melhores condições de educação não significa ser esse motivo menos importante para os migrantes mais velhos, mas apenas reflete seu menor 
sensivelmente o número de migrantes que se mudaram para a cidade à procura de educação escolar, as mulheres que indicaram esse motivo para sua migração passam a ser numericamente superiores aos homens, como mostra a Tabela 3. Não existem evidências que expliquem satisfatoriamente esse comportamento da migração por sexo, mas é provável que, na concepção da família, o rapaz adapte-se mais facilmente que a jovem a um ambiente desconhecido e adverso, em muitos sentidos. Talvez, justamente por não terem a oportunidade de se mudar para a cidade quando jovens, muitas mulheres o fazem mais tarde e em maior número que os homens.

Os dados disponíveis mostram que as causas da migração dos Sateré-Mawé para as cidades, por idade e sexo dos migrantes, não se modificaram substancialmente no decorrer do tempo. Nos 10 anos antes pesquisa de campo, elas mantiveram-se praticamente as mesmas que as verificadas em períodos anteriores. ${ }^{7}$

Mesmo para os mais idosos (50 anos ou mais), os motivos da migração não parecem diferenciar-se significativamente dos que foram declarados por os migrantes das demais faixas etárias. No entanto, a quantidade reduzida de migrantes idosos não permite avançar hipóteses confiáveis dos motivos que os levaram a procurar a vida urbana.
Em especial, os movimentos migratórios causados pela procura de melhores condições de ensino parecem manter, no conjunto dos motivos de migrar dos Sateré-Mawé, a mesma relevância no decorrer do tempo.

\section{Tempo de residência nas cidades}

As cidades de Parintins e Barreirinha são os destinos da maior parte dos migrantes nascidos na Terra Indígena Andirá-Marau e da quase totalidade dos nascidos especificamente na área do Andirá, um dos três componentes daquela terra indígena (as outras áreas são o Marau e o Uaicurapá). Isso ocorre devido à pouca distância que separa o Rio Andirá daquelas duas cidades. Já a cidade de Maués, sede do município banhado pelo Rio Marau, constitui a referência geográfica urbana principal para os Sateré-Mawé residentes na bacia desse rio.

Considerando-se os dados disponibilizados pelo Diagnóstico Sócio-Demográfico Participativo, é relativamente recente a migração com destino às cidades próximas das terras habitadas pelos SateréMawé. De fato, em 2003, 67,2\% dos migrantes moravam nessas cidades havia menos de 10 anos e, desses, dois terços tinham menos de cinco anos

Tabela 4 - Cidades de Parintins, Barreirinha, Maués e Nova Olinda do Norte Tempo de moradia dos migrantes - 2002/2003

\begin{tabular}{l|c|c|c|c|c}
\hline \multirow{2}{*}{ Tempo de residência } & \multicolumn{5}{|c}{ Cidade de residência atual } \\
\cline { 2 - 6 } & Barreirinha & Maués & $\begin{array}{c}\text { Nova Olinda } \\
\text { do Norte }\end{array}$ & Parintins & Total \\
\hline Menos de 1 ano & 5,6 & 24,6 & 14,3 & 9,5 & 11,9 \\
\hline De 1 a 4 anos & 42,5 & 41,8 & 0 & 25 & 33,2 \\
\hline De 5 a 9 anos & 24,4 & 21,6 & 42,9 & 22,6 & 23,1 \\
\hline 10 anos ou mais & 27,5 & 11,9 & 42,9 & 42,9 & 31,8 \\
\hline Total & 100 & 100 & 100 & 100 & 100 \\
\hline Número de migrantes & 160 & 130 & 7 & 273 & 570 \\
\hline População com 10 anos ou mais de idade & 190 & 145 & 7 & 346 & 688 \\
\hline
\end{tabular}

Fonte: Base de dados do Diagnóstico Sócio-Demográfico Participativo da População Sateré-Mawé.

contingente demográfico em relação aos jovens (Eles são 205, contra 375 com menos de 30 anos de idade).

${ }^{7}$ Mesmo para os mais idosos (50 anos ou mais), os motivos da migração não parecem diferenciar-se significativamente dos que foram declarados por os migrantes das demais faixas etárias. No entanto, a quantidade reduzida de migrantes idosos não permite avançar hipóteses confiáveis dos motivos que os levaram a procurar a vida urbana.

de residência. Conforme as indicações fornecidas pelos dados levantados, o destino anterior dos fluxos migratórios concentrava-se quase exclusivamente em Barreirinha e Parintins, tendo sido de- 
pois redirecionado, em grande parte, para Maués. Excetuando-se Nova Olinda do Norte (que tem um total de apenas 10 moradores Sateré-Mawé), Maués é a cidade com a maior proporção (92\%) de migrantes na população com 10 anos ou mais de idade, isto é, a população Sateré-Mawé que ali reside - com exceção das crianças - é constituída praticamente por migrantes.

Com a devida cautela, pode-se inferir que a migração em maior escala dos Sateré-Mawé em direção às cidades próximas às terras indígenas se tenha iniciado aproximadamente 30 anos antes da realização do Diagnóstico Sócio-Demográfico Participativo (Teixeira, 2005). Isso porque 90\% dos naturais dessas cidades têm idade acima de 30 anos, ${ }^{8}$ isto é, nasceram a partir dos primeiros anos da década de setenta, o que sugere que os migrantes (pais dos naturais) mais antigos teriam, em sua grande maioria, pouco mais de 30 anos de moradia.

Além de indicar uma perda de população da área do Marau para a cidade de Maués, os dados disponíveis (Tabela 5) mostram uma perda ainda maior da área do Andirá, devido à migração

Tabela 5 - Cidades de Parintins, Barreirinha, Maués e Nova Olinda do Norte - Área indígena de nascimento por cidade de residência atual - 2002-2003

\begin{tabular}{l|c|c|c|c|c}
\hline \multicolumn{7}{c}{ residência atual - 2002-2003 } \\
\hline \multirow{2}{*}{ Bidade de residência } & \multicolumn{5}{|c}{ Área indígena de nascimento } \\
\cline { 2 - 6 } & Andirá & Maraus & Outras & Não sabe & Total \\
\hline Maués & 95 & - & - & - & 95 \\
\hline Nova Olinda do Norte & 2 & - & - & - & 2 \\
\hline Parintins & 9 & 105 & 3 & - & 117 \\
\hline Total & 223 & 5 & 4 & 1 & 232 \\
\hline
\end{tabular}

Fonte: Base de dados do Diagnóstico Sócio-Demográfico Participativo da População Sateré-Mawé.

Obs. Os migrantes não-contabilizados na tabela são originários de outros locais, em especial da área rural adjacente à Terra Indígena Andirá-Marau.

para Parintins e Barreirinha, mas não apenas para essas duas cidades. Os Sateré-Mawé do Andirá povoaram a área do Rio Uaicurapá e a aldeia SateréMawé situada no Koatá-Laranjal, além de se terem estabelecido, em grande número, em Manaus, ca-

\footnotetext{
${ }^{8}$ Dos 108 moradores com 10 anos ou mais nascidos nas quatro cidades em estudo, apenas 11 tinham idade superior a 30 anos, sendo dois, em média, por grupo quinquenal, até os 50 anos, e três somente a partir daí.
}

pital do Amazonas. Os moradores das cidades vizinhas e das áreas do Uaicurapá e do Koatá-Laranjal receberam 556 migrantes do Andirá e 291 do Marau. Apenas de Ponta Alegre, aldeia do Andirá, saíram 69 dos 160 imigrantes de Barreirinha e 168 dos 296 de Parintins. A soma desses dois valores representava $60 \%$ dos 397 moradores da referida comunidade em 2003. Caso se considere apenas a população com idades entre 10 a 49 anos, o número de migrantes que deixou Ponta Alegre será bem superior à respectiva população (237 migrantes para 199 moradores na faixa etária).

\section{MIGRAÇÃO PARAMANAUS}

\section{Contextualização do processo migratório}

Localizada no coração do estado do Amazonas, a cidade de Manaus constitui a principal referência urbana para a maioria dos migrantes - indígenas e não-indígenas - desse estado e, inclusive, no caso específico dos primeiros, por ter o estado de Amazonas o maior contingente de indígenas do país. Cidade cuja população superou um milhão e seiscentos mil habitantes em 2007, ${ }^{9}$ Manaus tornou-se, a partir de 1970, quando tinha menos de 300 mil habitantes, o destino escolhido por expressivos fluxos de migrantes do interior e de outros estados da Federação, especialmente das regióes Norte e Nordeste. Contando com um parque industrial moderno e dinâmico, fruto dos subsídios da Zona Franca de Manaus, apresenta intensa atividade no comércio e nos serviços, cujos empregos são disputados por naturais e migrantes. Sua população indígena, de quase oito mil habitantes em 2000 e estimada atualmente em pouco mais de 10 mil, ${ }^{10}$ é composta, em grande maioria, por migrantes provenientes das terras indígenas do estado do Amazonas e por seus filhos.

${ }^{9}$ IBGE, Contagem da População de 2007.

${ }^{10}$ Estimativa dos autores. 
Foi nas décadas imediatamente anteriores a 1990 que chegou a Manaus a maioria dos migrantes da cidade. Os anos setenta e oitenta presenciaram um crescimento populacional da cidade extraordinário e inédito, com uma média anual de aproximadamente $6,5 \%$.

Remonta a vários séculos o movimento migratório indígena em direção a Manaus, o qual se intensificou durante o ciclo da borracha (séculos XIX e XX). No entanto, foi a partir da criação da Superintendência da Zona Franca de Manaus (SUFRAMA) que a migração tornou-se um movimento contínuo. Segundo depoimento de um líder indígena do Alto Rio Negro (estado do Amazonas), a propaganda governamental da época apregoava que os indígenas poderiam ter uma vida melhor trabalhando na cidade (Barretto, 2002).

Os indígenas residentes em Manaus provêm de todo o interior do estado e representam a grande maioria das etnias amazonenses. Não há dados globais confiáveis a respeito da repartição étnica dos indígenas que migraram para Manaus, mas sabe-se que eles são originários das terras indígenas de maior concentração populacional, entre as quais se sobressaem as que se situam no Alto Rio Negro e no Alto Solimões. O levantamento estatístico que doravante abordaremos indica que, entre as etnias mais presentes na cidade, encontram-se os Ticuna e Cokama, do Alto Solimões, os Tucano, Baré, Dessana e Tariano, do Alto Rio Negro e os Sateré-Mawé, do Médio Amazonas.

De uma forma geral, a dimensão e a intensidade dos fluxos migratórios de cada etnia para Manaus dependem tanto de seu volume populacional nas áreas de origem como da quantidade de moradores da mesma etnia que reside na capital amazonense. Não seria exagero afirmar que quanto maior a rede social constituída por um determinado povo indígena na cidade, maior a propensão dos membros desse povo nas áreas indígenas a migrar com destino a Manaus (Mainbourg et al., 2008).

Conforme mencionado, não há indicação segura da quantidade de Sateré-Mawé ou de membros de outras etnias em Manaus. Sua estimação é dificultada pela falta de parâmetros confiáveis para os cálculos correspondentes. Na elaboração de sua dissertação de mestrado, em 1982, Romano chegou a contabilizar 88 indígenas pertencentes a esse povo na cidade. De forma muito aproximada, estima-se que seu número possa ser situado entre 600 e 700 pessoas em 2008, admitindo-se a hipótese que os Sateré-Mawé têm, sobre a população indígena da cidade, o mesmo peso que seus efetivos estaduais tinham em 2000 sobre o total de indígenas do estado do Amazonas (aproximadamente nove mil Sateré-Mawé, num total de 113 mil indígenas no estado). ${ }^{11}$

A Tabela 6 mostra a distribuição da amostra da pesquisa realizada em 2007 em Manaus, segundo a etnia dos entrevistados.

Tabela 6 - Cidade de Manaus - Número de indígenas entrevistados, por etnia - 2007

\begin{tabular}{l|c}
\hline Povo indígena & Entrevistados \\
\hline Sateré-Mawé & 164 \\
\hline Tukano & 125 \\
\hline Tikuna & 76 \\
\hline Baré & 70 \\
\hline Dessana & 44 \\
\hline Cokama & 46 \\
\hline Tariano & 38 \\
\hline Apurinã & 27 \\
\hline Mura & 24 \\
\hline Outros & 144 \\
\hline Total & 753 \\
\hline
\end{tabular}

Fonte: Extraído de Mainbourg et al., 2008

Com uma distribuição etária mais jovem que a da população indígena urbana do Brasil em 2000, os indígenas de Manaus apresentam uma repartição por sexo marcadamente favorável às mulheres. Essa característica é verificada em quase todos os grupos etários, principalmente nas idades economicamente ativas, e está relacionada à maioria nitidamente feminina nos fluxos migratórios para a cidade (Mainbourg et al., 2008). A repartição por sexo e idade dos Sateré-Mawé assemelha-se à dos demais povos indígenas numericamente importantes na cidade.

${ }^{11}$ A população sateré-mawé em 2000 pode ser estimada como uma retroprojeção dos efetivos contabilizados no Diagnóstico Sócio-Demográfico Participativo de 2002/ 2003, listados anteriormente na Tab. 1 deste trabalho (8.500 nas terras indígenas e cidades vizinhas e de 500 a 600 em Manaus). 
Quanto à migração indígena, é necessário ressaltar inicialmente sua importância na composição da população indígena de Manaus. Dois terços dos entrevistados com idade igual ou superior a 10 anos não são naturais da cidade. Proporcionalmente, eles superam em muito os migrantes nãoindígenas, que correspondem à metade do total de entrevistados não-indígenas.

Quase 77\% dos migrantes indígenas entrevistados nasceram em terra indígena. O restante nasceu em áreas urbanas ou rurais situadas na proximidade das terras indígenas, ou - em poucos casos - em outros locais (outros municípios amazonenses ou de outros estados).

A proporção de migrantes na população etnia. Entre as mais representadas na cidade, os Tukano e os Cokama constituem as maiores proporções de migrantes (80\%). Os Sateré-Mawé apresentam a menor proporção de migrantes (53\%) no total de moradores da etnia, correspondendo a 80 entre os 151 residentes entrevistados sobre migração. O presente estudo passa a adotar esse total de migrantes como base para as considerações que se seguirão. Apesar da pequena quantidade, poderão ser levantados elementos interessantes para a análise, especialmente na comparação de algumas características dos migrantes de Manaus, distante das terras indígenas dos Sateré-Mawé, com os de cidades próximas àquelas terras. indígena entrevistada em Manaus varia segundo a

\section{Características demográficas e motivos da migração dos Sateré-Mawé para Manaus}

Conforme visto em parágrafo anterior, há uma maioria feminina entre os indígenas de Manaus, o que deve estar relacionado à maior imigração das mulheres indígenas. De fato, elas são mais numerosas que os homens entre os migrantes indígenas, representando 261 dos 452 entrevistados (58\%). Como os não-migrantes indígenas repartem-se em proporções quase iguais de homens e mulheres, o diferencial por sexo, no total da população, fica sendo determinado pela superioridade feminina entre os migrantes.

Os migrantes Sateré-Mawé apresentam uma participação feminina ainda mais elevada $(65 \%)^{12}$ que para a população total indígena de Manaus. Assim como para o conjunto dos povos indígenas da cidade, a diferença quantitativa a favor das mulheres entre os Sateré-Mawé migrantes é quase idêntica à do total dos moradores dessa etnia. Isto equivale a afirmar que homens e mulheres naturais de Manaus (não-migrantes) são quase iguais em quantidade ( 34 e 30 pessoas, respectivamente). Em consequência, a maioria feminina na população Sateré-Mawé em Manaus deve-se quase inteiramente à forte migração feminina para a cidade.

Quando se analisam conjuntamente o sexo e a idade dos migrantes Sateré-Mawé em Manaus, observa-se uma situação distinta da observada para as cidades próximas à Terra Indígena AndiráMarau e já retratada neste trabalho. De um lado, como já discutido, a proporção de mulheres entre os migrantes de Manaus é superior aos 51,4\% encontrados nas cidades mencionadas. De outro, a

Tabela 7 - Cidade de Manaus - Número de migrantes sateré-mawé e de todas as etnias da amostra segundo a condição de migração - 2007

\begin{tabular}{l|c|c|c|c|c|c}
\hline \multirow{2}{*}{ Condição de naturalidade } & \multicolumn{3}{|c|}{ Sateré-Mawé } & \multicolumn{2}{c}{ Todas as etnias } \\
\cline { 2 - 8 } & Homens & Mulheres & Total & Homens & Mulheres & Total \\
\hline Não-migrantes & 34 & 37 & 71 & 128 & 132 & 260 \\
\hline Migrantes & 28 & 52 & 80 & 191 & 261 & 452 \\
\hline Total & 62 & 89 & 151 & 319 & 393 & 712 \\
\hline Fonte: Base de dados da pesquisa População Indígena da Cidade de Manaus: Condições de Saúde e SUS. \\
$\begin{array}{c}\text { 12 Essa diferença de 7\% entre as mulheres Sateré-Mawé e } \\
\text { o total de mulheres migrantes deve ser tomada com cau- } \\
\text { tela, devido à dimensão reduzida da amostra de migrantes } \\
\text { Sateré-Mawé entrevistados (80 moradores). }\end{array}$
\end{tabular}


superioridade feminina não varia significativamente nos grandes grupos etários (0-14, 15-59, 60 anos e mais) na capital amazonense, contrariamente ao observado nas demais cidades, onde a distribuição etária desigual entre homens e mulheres estaria a indicar causas distintas para a migração de adolescentes, jovens e adultos segundo o sexo.

Em média, os migrantes Sateré-Mawé de Manaus têm idade mais elevada do que os que se destinaram às cidades interioranas estudadas. São $57,5 \%$ os de 30 anos e mais entre os primeiros e apenas 36\% entre os últimos. Ao contrário do que ocorre naquelas outras cidades, em que um de cada cinco migrantes tem menos de 15 anos de idade, a proporção em Manaus desses adolescentes é de apenas um para 12. Os migrantes da capital amazonense com 10 a 19 anos de idade representam menos de $20 \%$ do total, ao passo que as cidades próximas à área indígena têm mais que o dobro dessa cifra.
Assim, diferentemente do que ocorre nas cidades vizinhas da Terra Indígena Andirá-Marau (Tabela 3), já examinada, a migração por motivos educacionais parece ser irrisória em Manaus. Pouco mais de 10\% dos imigrantes Sateré-Mawé da cidade declararam a busca de oportunidades educacionais como motivo para migrar. Naquelas outras cidades, esse motivo era citado por metade (49\%) dos imigrantes. A procura de trabalho como causa da migração foi pouco mencionada pelos Sateré-Mawé nas referidas cidades (4\% dos migrantes), mas constitui a principal causa dos deslocamentos para Manaus, tendo sido referida por 38\% dos imigrantes da capital amazonense. É interessante mencionar que os 80 migrantes Tukano da amostra de Manaus (mesmo quantidade dos Sateré-Mawé) declararam igualmente a procura de trabalho e os motivos educacionais como causas da migração, citadas, cada uma, por 31\% dos entrevistados.

Tabela 8 - Cidade de Manaus - Etnia Sateré-Mawé

Idade, por sexo, segundo a condição de migrante ou não-migrante2007

\begin{tabular}{l|c|c|c|c|c|c|c|c}
\hline \multirow{2}{*}{$\begin{array}{l}\text { Condição de } \\
\text { migração }\end{array}$} & \multicolumn{2}{|c|}{$\mathbf{1 0 - 1 9}$ anos } & \multicolumn{2}{c|}{$\mathbf{2 0 - 2 9}$ anos } & \multicolumn{2}{|c|}{ 30 anos e mais } & \multicolumn{2}{c}{ Total } \\
\cline { 2 - 10 } & Masc. & Fem. & Masc. & Fem. & Masc. & Fem. & Masc. & Fem. \\
\hline Não-migrantes & 5 & 9 & 8 & 12 & 15 & 31 & 28 & 52 \\
\hline Migrantes & 13 & 10 & 21 & 28 & 0 & 0 & 34 & 38 \\
\hline Total & 18 & 19 & 29 & 40 & 15 & 31 & 62 & 90 \\
\hline
\end{tabular}

Fonte: Base de dados da pesquisa População Indígena da Cidade de Manaus: Condições de Saúde e SUS.

Provavelmente, a razão dessa diferença é que

Manaus estaria a atrair menos migrantes SateréMawé adolescentes e jovens que desejam continuar os estudos, permanecendo a maioria dos migrantes desses contingentes etários nas cidades próximas à terra indígena de nascimento, usufruindo, ali, da assistência contínua dos pais que mensalmente vão receber salários e aposentadoria. Essa relação "administrativa” da área indígena com as cidades vizinhas daria às famílias, em contrapartida, a segurança de um contato permanente com os filhos. Tais condições, evidentemente, não se repetem para Manaus, em que os migrantes Sateré-Mawé não mantêm tal tipo de relação com a terra natal, pois o acesso dispendioso não permite viagens amiúde num ou noutro sentido.
De forma também diferente do que ocorre com os migrantes das cidades próximas da Terra Indígena Andirá-Marau, não se observa, em Manaus, variabilidade significativa na repartição por sexo e idade dos migrantes. Nessa última cidade, as mulheres migrantes Sateré-Mawé são numericamente superiores aos homens em praticamente todas as faixas etárias, com pequenas exceções sem significância estatística.

\section{Tempo de residência dos migrantes}

Uma forma de melhor compreender a distribuição etária dos migrantes Sateré-Mawé e algumas determinações da migração é o exame do tem- 
po de migração, indicado, no caso presente, pelos anos de residência em Manaus.

Assim como o que ocorre para os não-indígenas, o tempo de residência de um migrante indígena no local de destino depende de vários fatores, como a conjuntura econômica, social ou política à época da migração, o motivo da migração, a idade e o sexo do migrante, a distância entre a área de origem e a de destino, o alcance dos meios de comunicação, as condições de vida dos parentes no local de destino e outros. Conforme já comentado, as migrações indígenas com destino a Manaus, em seu período mais intenso - a partir dos anos setenta -, ocorreram no âmbito dos intensos fluxos migratórios atraídos pelas oportunidades de emprego criadas com a implantação da Zona Franca de Manaus (1967).

As informações levantadas na pesquisa da FIOCRUZ realizada em Manaus em $2007^{13}$ indicam que $40 \%$ dos migrantes indígenas residiam na cidade desde pelo menos duas décadas antes do ano do levantamento de campo. A proporção eleva-se a $70 \%$ quando se consideram os migrantes com 10 anos ou mais de residência, isto é, que chegaram a Manaus antes de 1997. Os 30\% restantes fizeram a migração a partir desse último ano.

Não há diferença notável entre os SateréMawé e o conjunto dos demais povos indígenas em relação ao tempo de residência na cidade de Manaus. A quase equivalência mantém-se quando se incorporam o sexo e a idade na análise. Tais constatações estariam a indicar uma independência do processo migratório em relação à etnia quando se consideram o sexo e a idade dos migrantes, ou seja, que os diferentes povos indígenas - pelo menos os mais representativos na amostra estudada - mostram comportamento comum (segundo sexo e idade) em relação à tendência migratória nas últimas quatro décadas.

Há, no entanto, uma diferença marcante entre o tempo de migração dos Sateré-Mawé em Manaus e o correspondente nas cidades que têm servido como referência para este estudo. Se, como afirma-

${ }^{13}$ População Indígena da Cidade de Manaus: Condições de Saúde e SUS do, cerca de 70\% dos migrantes Sateré-Mawé de Manaus residiam na cidade antes de 1997, o mesmo não ocorre com os residentes dessa etnia no interior do estado. Conforme indicado no item referente à migração dos Sateré-Mawé em áreas urbanas próximas à sua terra indígena, no ano de $2003,{ }^{14}$ as cidades de Barreirinha, Parintins, Maués e Nova Olinda do Norte apresentavam, em seu conjunto, apenas 31\% de migrantes Sateré-Mawé com 10 anos ou mais de residência. Em Maués, o percentual respectivo não passava dos $12 \%$.

Há duas possibilidades de explicação para essa diferença expressiva de tempo entre as migrações sateré-mawé de Manaus e o interior do estado. A primeira é de que a migração de Manaus á mais antiga, pelo menos no que se refere ao volume migratório em cada época. Como foi visto, o início da migração mais acentuada - embora ainda reduzida - para as cidades citadas data de aproximadamente 30 anos antes de 2003, talvez um pouco mais recente que a referente a Manaus. Todavia, nessa última cidade, pode-se deduzir - como será feito adiante-que os fluxos migratórios dos SateréMawé nos anos setenta foram bem mais intensos que os verificados naquelas cidades do interior. Outra forma de explicar a maior atualidade da migração para cidades próximas à terra dos SateréMawé estaria na elevada proporção de migrantes recentes (menos de 10 anos de moradia) naquelas cidades. De fato, eles representavam $70 \%$ do total de migrantes em 2003, tendo um peso, portanto, muito maior do que os $30 \%$ contabilizados em Manaus quatro anos depois.

Uma forma de procurar quando se iniciou - ou se intensificou - o processo migratório de um agrupamento populacional um determinado local está na distribuição etária dos não-migrantes nesse local. Se um morador não-migrante é filho de um pai migrante, o ano de mudança do pai para o local de moradia atual é obrigatoriamente anterior ao do nascimento do filho. A queda abrupta desses efetivos a partir de uma determinada idade indicaria uma redução - também abrupta - da mi-

${ }^{14}$ Ano de realização do Diagnóstico Sócio-Demográfico Participativo da População Sateré-Mawé, já citado. 
gração (dos pais) em épocas imediatamente anteriores às datas de nascimentos dos filhos. ${ }^{15}$ É o que ocorreu, por exemplo, nas cidades vizinhas às terras dos Sateré-Mawé, onde foi visto que a imigração em maior escala dos Sateré-Mawé teria começado aproximadamente 30 anos antes da realização do Diagnóstico Sócio-Demográfico Participativo da População Sateré-Mawé (2003), isto é, por volta do início dos anos setenta. Isso porque praticamente não havia moradores naturais daquelas cidades com idade superior a 30 anos. No caso de Manaus, em 2007, para 221 indígenas nãomigrantes (todas as etnias), havia 16 com idade entre 30 e 39 anos e apenas dois com 40 ou mais anos de idade, indicando que, na amostra estudada, havia um número irrisório de indígenas que tenham chegado a Manaus mais de 40 anos antes de 2007. Não seria de se descartar, pois, a influência da implantação da Zona Franca de Manaus, em 1967, sobre a intensificação da migração indígena para a cidade, confirmando o depoimento, já citado, de um líder indígena do estado do Amazonas (Barretto, 2002).

\section{CONSIDERAÇÕES FINAIS}

A migração indígena para as áreas urbanas da Amazônia e, em particular, para o estado do Amazonas, tem acompanhado o processo migratório da população regional como um todo na segunda metade do Século XX, em especial o que se deu com a implementação dos grandes projetos de ocupação territorial na segunda metade dos anos sessenta. No caso específico da migração para Manaus, sua intensificação teria ocorrido a partir da implementação da Zona Franca, em 1967. Todavia, há indícios de que, nessa época, já se avolumava a migração dos territórios indígenas para as cidades próximas a eles.

Data também aproximadamente da mesma época o início dos movimentos migratórios do povo

${ }^{15}$ Supõe-se, aqui, que a quase totalidade dos pais migrantes tenham tido filhos que nasceram na cidade de residência e que não haja mortalidade entre os pais migrantes.
Sateré-Mawé, tanto em direção a Manaus como para áreas urbanas próximas à área indígena. Os dados obtidos em dois levantamentos de campo realizados em 2002 e 2003 (terra indígena e cidades vizinhas) e em 2007 (Manaus) permitem esboçar algumas características demográficas e sociais desses deslocamentos e traçar comparações entre o processo migratório para um e outro destino.

Em suas características gerais, a migração dos Sateré-Mawé - povo indígena do leste amazonense - para Manaus não difere essencialmente da que se verifica para as demais etnias do estado. Entre as exceções no campo demográfico, está a maior participação feminina na migração dos Sateré-Mawé que no conjunto dos demais povos.

Os motivos da migração são basicamente os mesmos, com destaque para a procura de trabalho e de melhores condições de educação. No entanto, a proporção de entrevistados que indica um ou outro motivo pode variar. Como exemplo, entre os Sateré-Mawé de Manaus, são mais numerosos os migrantes que apontam a procura de trabalho como causa da migração do que os que indicam a educação, ao passo que, entre os Tukano, os dois motivos são declarados pelo mesmo número de entrevistados.

Procura de trabalho e busca de melhores condições de ensino são também os principais motivos da migração dos Sateré-Mawé que saem de suas terras em direção às cidades próximas. Em Manaus, as duas causas caminham em direção oposta. Se, naquelas cidades do interior, a educação é declarada como o principal motivo para a migração, e a procura de trabalho apresenta importância apenas marginal, em Manaus, a procura de trabalho é a mais citada, como observado anteriormente, e a educação, embora não se mostre de todo irrelevante, é referida por um número significativamente menor de migrantes.

Provavelmente relacionada à situação descrita está a menor juventude da população SateréMawé que se dirige a Manaus. A razão disso poderia ser buscada na atração menor exercida por Manaus sobre os estudantes jovens, os quais tendem a migrar para cidades próximas, onde podem 
usufruir da assistência e do apoio contínuos dos pais, que mensalmente vão receber salários e aposentadoria. A isso vale acrescentar o fato de que a Universidade Federal do Amazonas e a Universidade do Estado do Amazonas criaram campi avançados em cidades do interior, alguns próximos a áreas indígenas, como Parintins e Maués.

Distintamente do que ocorre com os migrantes Sateré-Mawé das cidades interioranas em foco, em que a participação feminina é apenas um pouco superior à dos homens, em Manaus, as mulheres são mais de dois terços do total de migrantes. Naquelas cidades, apesar dessa reduzida maioria feminina, a acentuada variabilidade na quantidade de homens e mulheres, quando se considera a idade, permitiu levantar a hipótese de causas diferentes para a migração de adolescentes, jovens e adultos segundo o sexo. O mesmo não pôde ser confirmado para o caso de Manaus, já que, apesar da ampla superioridade numérica das mulheres na população migrante, ela não varia significativamente em cada um dos grandes grupos etários (0-14, 15-59, 60 anos e mais), o que se poderia dever ao tamanho reduzido da amostra utilizada na obtenção das informações referentes à migração dos Sateré-Mawé.

(Recebido para publicação em julho de 2009) (Aceito em setembro de 2009)

\section{REFERÊNCIAS}

AZEVEDO, M. M. Demografia dos povos indígenas do Alto Rio Negro. Revista Brasileira de Estudos de População, Campinas, n.11, p.235-244. 1994.

Urbanização e migração na cidade de São Gabriel da Cachoeira, Amazonas. In: ENCONTRO NACIONAL DE ESTUDOS POPULACIONAIS, 15, 2006, Caxambu, Anais... Campinas: ABEP, 2006.

BAINES, S. G. As chamadas "aldeias urbanas” ou índios na cidade. Revista Brasil Indígena, Brasília,DF, v.1, n.7, nov./dez., 2001

BARRETTO, R. Fiocruz conclui pesquisa sobre a saúde dos índios urbanos em Manaus (AM). Disponível em: <www. socioambiental.org.br>. Acesso em: 31 dez., 2008.

BRASIL, M.; TEIXEIRA, P. Migração dos povos indígenas e os censos demográficos de 1991 e 2000: o caso das capitais estaduais. In: ENCONTRO NACIONAL DE ESTUDOS POPULACIONAIS,15, 2006, Caxambu, Anais.. Campinas: ABEP, 2006.
CARVALHO, J. A. M. Migrações internas - mensuração direta e indireta. In: ENCONTRO NACIONAL DE ESTUDOS POPULACIONAIS,2, 1980, Águas de São Pedro, Anais... São Paulo: ABEP, 1980.

COIMBRA JR., C. E. E.; Santos, R.V. Saúde, minorias e desigualdade: algumas teias de inter-relações, com ênfase nos povos indígenas no Brasil. Ciência e Saúde Coletiva, Rio de Janeiro, v.5, n.1, 2000.

DIAS JÚNIOR, C. S. et al. Crescimento da população indígena em Minas Gerais: uma análise da influência da dinâmica demográfica e reclassificação racial a partir dos dados censitários de 1991/2000. In: ENCONTRO NACIONAL DE ESTUDOS POPULACIONAIS, 16, 2008 , Caxambu, Anais... Campinas: ABEP, 2008.

FIGOLI, Leonardo H. Identidad étnica y regional: trayecto constitutivo de uma identidad social. 1982. Dissertação (Mestrado em Antropologia) - Universidade Nacional de Brasília. 1982.

IBGE. Tendências demográficas: uma análise dos indígenas com base nos resultados da amostra dos censos demográficos 1991 e 2000. Rio de Janeiro: IBGE, 2005. (Estudos e pesquisas, n.17)

MAINBOURG, E. M. T. et al. População indígena da cidade de Manaus: demografia e SUS. In: ALMEIDA, A.W.B.; SANTOS, G.S.S. Estigmatização e território: mapeamento situacional dos indígenas em Manaus. Projeto Nova Cartografia Social da Amazônia. Manaus: Ed. Universidade Federal do Amazonas, 2008.

OLIVEIRA, T. P. P. O crescimento da presença indígena nos censos nacionais 1991-2000: uma análise da região Nordeste. In: ENCONTRO NACIONAL DE ESTUDOS POPULACIONAIS,16, 2008, Caxambu, Anais... Campinas: ABEP, 2008.

PEREIRA, N. O. M.; AZEVEDO, M. M. Os povos indígenas e os censos do IBGE: uma experiência brasileira. In: CONGRESSO INTERNACIONAL DA ASSOCIACÃO LATINO-AMERICANA DE POPULAÇÃ O,1, 2004. Caxambu, Anais... Caxambu: ALAP. 2004.

et al. Perfil demográfico e sócio-econômico das $\overline{\text { pessoas }}$ que se auto-declararam "indígenas" nos censos demográficos de 1991 e 2000. In: PAGLIARO, H. et al. (Org.) Demografia dos povos indígenas no Brasil. Rio de Janeiro: Ed. FIOCRUZ; Campinas: ABEP, 2005.

PINHO, B. A. T. D; CAMPOS, M. B. Xakriabás: a mobilidade como estratégia de sobrevivência. In: ENCONTRO NACIONAL DE ESTUDOS POPULACIONAIS,16, 2008, Caxambu, Anais... Campinas: ABEP, 2008.

ROMANO, J. O. Índios proletários em Manaus: o caso dos Sateré-Mawé citadinos. 1982. Dissertação (Mestrado em Antropologia) - Universidade Nacional de Brasília. 1982.

SENA, R. R. Movimentos migratórios da população saterémawé: povo indígena da Amazônia. 2007. 90 f. Dissertação (Mestrado em Desenvolvimento Regional) - Programa de Pós-Graduação em Desenvolvimento Regional da Universidade Federal do Amazonas. Manaus, 2007.

TEIXEIRA, P. (Org.) Sateré-Mawé: retrato de um povo indígena. Manaus: UNICEF/FNUAP, 2005. 147 p.

; SENA, R. R. As migrações entre os Sateré-Mawé, povo indígena da Amazônia Brasileira. In: ENCONTRO NACIONAL DE ESTUDOS POPULACIONAIS,16, 2008, Caxambu, Anais... Campinas: ABEP, 2008.

; BRASIL, M. C. Migração, urbanização e características da população indígena do Brasil através da análise dos dados censitários de 1991 e 2000. In: CONGRESO DE LA ASOCIACIÓN LATINOAMERICANA DE POBLACIÓN,3, 2008, Anais... Córdoba, Ar. 2008. 


\section{MIGRATION OF THE SATERÉ-MAWÉ INDIGENOUS PEOPLE IN TWO DIFFERENT URBAN CONTEXTS IN THE AMAZON}

\author{
Pery Teixeira \\ Evelyne Marie Therese Mainbourg \\ Marília Brasil
}

Gathering information in two field researches - one censitary and one by sampling - regarding different urban areas of the state of Amazon, this work tries to supply subsidies for the understanding of the indigenous migration with urban destiny in the Amazon basin, mainly focusing in the SateréMawé indigenous people. It is a comparative study among migratory characteristics of Sateré-Mawé resident in Manaus, capital of the state of Amazon, and living in the cities close to the indigenous lands of origin of that people, in the east of the state. In spite of the similarity of some of the characteristics of the migratory process in both contexts motivated by the job search and for educational opportunities, differentiation is observed in the importance of those causes in each context, other than distinctions in age and gender group in the migrants.

KEYWORDS: migration of Indigenous people, SateréMawé, demography of Indigenous people, brazilian indigenous peoples.

\section{MIGRATION DU PEUPLE INDIGENE SATERÉ- MAWÉ DANS DEUX CONTEXTES URBAINS DISTINCTS EN AMAZONIE}

\author{
Pery Teixeira \\ Evelyne Marie Therese Mainbourg \\ Marília Brasil
}

Basé sur des informations obtenues au cours de deux enquêtes réalisées sur le terrain - un recensement et un échantillonnage - relatives à des zones urbaines différentes dans l'Etat d'Amazonas, ce travail permet de fournir des éléments qui permettent de mieux comprendre la migration indigène vers les zones urbaines en Amazonie, en mettant essentiellement l'accent sur la population indigène Sateré-Mawé. Il s'agit d'une étude comparative entre les caractéristiques migratoires des Sateré-Mawé résidents à Manus, capitale de l'Etat d'Amazonas et ceux qui habitent dans les villes proches des terres indigènes d'origine de ce peuple, à l'est de l'Etat. Malgré certaines caractéristiques similaires du processus migratoire dans ces deux contextes - motivation pour la recherche d'un travail et opportunités d'instruction - on observe une différence au niveau de l'importance de ces causes dans le cadre de chaque contexte, sans compter les différences au niveau des tranches d'âge et de la répartition par sexe des migrants.

MoTS-CLÉs: migration des peuples indigènes, SateréMawé, démographie des peuples indigènes, Indiens.

Pery Teixeira - Doutor em Demografia pela Universidade Federal de Minas e pós-doutor pelo Centre Population et Développement (CEPED) - França. Professor Adjunto da Universidade Federal do Amazonas. Pesquisador e membro da Coordenação do Programa de Pós-Graduação em Desenvolvimento Regional daquela Universidade. Graduado em Matemática pelo Instituto de Matemática e Estatística da Universidade de São Paulo. Na Associação Brasileira de Estudos de População coordena o Grupo de Trabalho sobre Demografia dos Povos Indígenas. Publicou diversos artigos em periódicos científicos e coordenou o Diagnóstico Sócio-Demográfico Participativo da População Sateré-Mawé, com relatório publicado pelo UNICEF em 2005. Áreas de atuação: mortalidade, migração, dinâmica demográfica e demografia indígena.

Evelyne Marie Therese Mainbourg - Doutora em Ciências Sociais pela Université de Tours. Pesquisadora da Fundação Oswaldo Cruz de Manaus e colaboradora do Centro de Ciências do Ambiente da Universidade Federal do Amazonas, lecionando e orientando no Programa de Pós-Graduação desta Universidade. Graduada pelo Institut d'Etude du Développement Economique et Social (IEDES) - Université de Paris I. Tem experiência na área de Saúde Coletiva, com ênfase em saúde indígena, atuando principalmente nos seguintes temas: condições de vida e de saúde das populações indígenas urbanas, saúde e ambiente, e uso de medicamentos e remédios caseiros.

Marília Brasil - Doutoranda em Saúde Coletiva pela Fundação Oswaldo Cruz (FIOCRUZ). Mestre em Demografia pelo Centro de Desenvolvimento e Planejamento Regional da Universidade Federal de Minas Gerais (CEDEPLAR/UFMG). Economista pela Universidade Federal do Pará. Atualmente é vinculada à Universidade Federal do Amazonas em seu Departamento de Economia e Análise. Atua especialmente na área de estudos populacionais, com especial ênfase nos temas de fecundidade, migração, urbanização e população indígena. 